\title{
Implementasi Socket Programming dalam Pembuatan Sistem Antrian Pembayaran di Unika dengan Metode FIFO
}

\author{
Mayshela Fithria Br.Sembiring ${ }^{1}$, Lamhot Sitorus ${ }^{2}$ \\ ${ }_{1,2}$ Universitas Katolik Santo Thomas, Jln. Setia Budi No.479-F Medan, 061-8210161, Indonesia
}

\section{ARTICLE INFORMATION}

Received: February 23,2019

Revised: March 19,2019

Available online: April 08,2019

\section{KEYWORDS}

First-in first-out,Antrian, Pembayaran

CORRESPONDENCE

Phone: +62813978623754

E-mail: lamhot86@gmail.com

\begin{abstract}
A B S T R A K
Penelitian ini dilakukan untuk menyelesaikan masalah yang ada pada pelayanan pembayaran dikampus. Sistem antrian dibuat menggunakan FIFO (First-In First-out), dimana mahasiswa yang datang lebih awal akan dilayani pertama dan pertama selesai. Aplikasi sistem antrian terdiri dari empat komputer, di mana tiga komputer digunakan sebagai layanan, dan komputer digunakan untuk memberikan nomor antrian yang akan menghasilkan / mencetak nomor antrian mahasiswa, juga menggunakan Kabel LAN untuk menghubungkan semua komputer yang akan terhubung. mahasiswa (Sistem Tampilan) dirancang untuk memberikan atau menampilkan informasi tentang nomor antrian ke mahasiswa dan total pembayaran, yang diharapkan membantu kelancaran mahasiswa dalam sistem pelayanan pembayaran.
\end{abstract}

\section{PENDAHULUAN}

Dalam kehidupan sehari-hari seseorang sering mengalami hal untuk menunggu antrian dengan waktu yang lama dan ini merupakan suatu hal yang sangat membosankan. Menunggu antrian yang panjang ini dapat disebabkan oleh kurangnya fasilitas untuk melayani masyarakat atau jumlah loket pelayanan yang ada belum memadai untuk melayani masyarakat, serta kurang sigapnya para pelayanan untuk melayani masyarakat atau konsumen. Contoh-contoh kasus antrian dalam kehidupan sehari-hari misalnya antrian pembelian tiket bioskop, antrian pembelian BBM, antrian mahasiswa membayar uang kuliah, antrian pada nasabah BANK, antrian pada simpul switching di jaringan data dan masih banyak lagi. Dengan adanya permasalahan di sistem antrian ini bisa mengakibatkan pelanggan marah,bosan, dan kehilangan pelanggan[1], [2].

Pelayanan yang diberikan kampus Universitas Katolik Santo Thomas melalui bagian pengajaran masih belum memadai, karena belum adanya suatu sistem layanan yang baik membuat mahasiswa dapat mengantri dengan teratur dan rapi. Oleh karena itu penulis mencoba untuk membuat suatu Implementasi Socket Programming dalam sistem antrian pembayaran uang kuliah di Universitas Katolik Santo Thomas dengan menggunakan metode FIFO dengan yang lebih efisien untuk mempermudah serta mempercepat segala kebutuhan mahasiswa menyangkut masalah pelayanan[3] [4].

Pada sistem antrian sisi lain yang banyak digunakan dalam bentuk perangkat keras yang jika suatu saat ada perubahan dalam instalasi maka seluruh perangkat harus diganti. Alternatif lain adalah sistem antrian yang dibuat dengan perangkat lunak yang berisi fitur multimedia. Sehingga memudahkan instalasi dan modifikasi perubahan yang terjadi. Dengan bantuan dari pemrograman socket memungkinkan untuk mengirim pesan antar komputer yang terhubung dalam sistem antrian, serta fitur multimedia tambahan lebih lanjut akan memberikan informasi yang menarik bagi pelanggan.

Berdasarkan uraian pada latar belakang masalah, maka yang menjadi rumusan masalah adalah "Bagaimana membuat sistem antrian pembayaran di Universitas Katolik Santo Thomas dengan mempermudah mahasiswa dalam pelayanan pembayaran".

\subsection{Konsep Dasar Teori Antrian}

\section{LANDASAN TEORI}

Teori antrian dikemukakan pada tahun 1909 oleh ahli matematika dan insinyur berkebangsaan Denmark yang bernama Agner Kraup Erlang. Penemuan itu terjadi ketika terdapat masalah kepadatan penggunaan telepon di Copenhagen Telephone. Erlang melakukan percobaan tentang fluktuasi permintaan sambungan telepon yang berhubungan dengan automatic dialing equipment, yaitu peralatan penyambungan telepon secara otomatis[5][6].

Proses antrian dimulai saat pelanggan-pelanggan yang memerlukan pelayanan mulai datang. Sebuah sistem antrian adalah suatu himpunan pelanggan, pelayan dan suatu aturan yang mengatur pelayanan kepada pelanggan. 
Menurut Bronson, Proses antrian adalah suatu proses yang berhubungan dengan kedatangan seorang pelanggan pada suatu fasilitas pelayanan kemudian menunggu dalam barisan atau antrian karena pelayanannya sedang sibuk dan akhirnya meninggalkan sistem setelah selesai dilayani.

Sebuah sistem antrian adalah suatu himpunan pelanggan, pelayan dan suatu aturan yang mengatur pelayanan kepada pelanggan. Sedangkan keadaan sistem menunjuk pada jumlah pelanggan yang berada dalam suatu fasilitas pelayanan, termasuk dalam antriannya. Salah satu populasi adalah jumlah pelanggan yang datang pada fasilitas pelayanan. Besarnya populasi merupakan jumlah pelanggan yang memerlukan pelayanan..

Dalam proses antrian, banyaknya populasi dibedakan menjadi dua, yaitu populasi terbatas (finite) dan populasi tidak terbatas (infinite). Populasi yang terbatas dapat ditemukan pada suatu perusahaan yang mempunyai sejumlah mesin yang memerlukan perawatan atau perbaikan pada periode tertentu. Populasi yang tidak terbatas merupakan pelanggan yang tidak terhingga yang contohnya dapat dilihat pada suatu supermarket, yang setiap hari melayani pelanggan yang datang secara random dan tidak dapat ditentukan berapa jumlahnya. Karena jumlah yang datang di supermarket tidak dapat ditentukan dengan pasti, yang karena sifatnya yang demikian kemudian disebut populasi yang tidak terbatas[7].

\subsection{Faktor Sistem Antrian}

Menurut Kakiay faktor-faktor yang berpengaruh terhadap barisan antrian dan pelayanannya adalah sebagai berikut :

a. Distribusi Kedatangan

Pola kedatangan para pelanggan biasanya dicirikan oleh waktu antar-kedatangan, yaitu waktu antara kedatangan dua pelanggan yang berurutan pada suatu fasilitas pelayanan. Pola ini dapat bergantung pada jumlah pelanggan yang berada dalam sistem, ataupun tidak bergantung pada keadaan sistem antrian ini.

b. Distribusi Waktu Pelayanan

Pola pelayanan biasanya dicirikan oleh waktu pelayanan (service time), yaitu waktu yang dibutuhkan seorang pelayan untuk melayani seorang pelanggan. Waktu pelayanan dapat bersifat deterministik, atau berupa suatu variabel acak yang distribusi probabilitasnya dianggap telah diketahui

c. Fasilitas Pelayanan

1. Bentuk seri, dalam satu garis lurus maupun garis melingkar.

2. Bentuk paralel, dalam beberapa garis lurus antara yang seri dengan yang paralel.

3. Bentuk rangkaian stasiun, yang dapat didesain secara seri dengan pelayanan lebih dari satu pada setiap stasiun. Bentuk ini dapat juga dilakukan secara paralel dengan stasiun yang berbeda-beda.

d. Disiplin Pelayanan

1. Disiplin pelayanan terbagi dalam empat bentuk, yaitu :

2. Pertama datang, pertama dilayani (FCFS $=$ first come first service)

3. Pelayanan dilakukan secara acak $(\mathrm{SIRO}=$ service in random order)

4. Pelayanan didasarkan pada prioritas khusus ( $\mathrm{PRI}=$ pelayanan prioritas)

5. Ukuran dalam antrian

6. Ukuran kedatangan secara tidak terbatas (infinite queue)

7. Ukuran kedatangan secara terbatas (finite queue)

8. Sumber Pemanggilan

9. Sumber pemanggilan tidak terbatas (infinite queue)

10. Sumber pemanggilan secara terbatas (finite queue)

\subsection{Struktur Dasar Teori Antrian}

Sistem antrian mencakup pelanggan (orang, mesin dan lain sebagainya) yang datang secara bergantian untuk mendapatkan layanan pada suatu fasilitas layanan. Proses suatu antrian dapat dilihat pada gambar 1 di bawah ini:

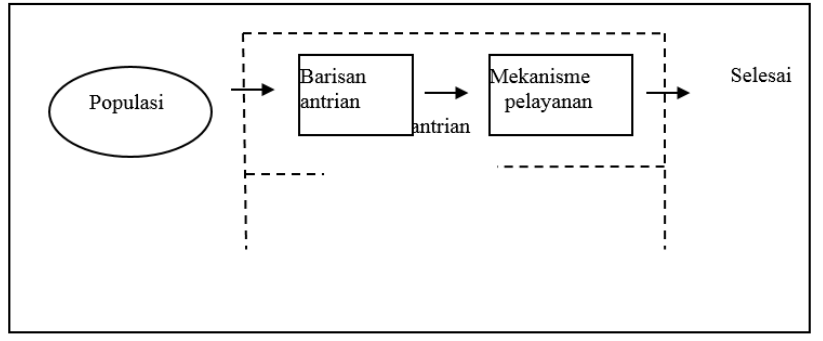

Gambar 1. Struktur Dasar Teori Antrian[6]

Soket merupakan fasilitas IPC (Inter-Process Communication) untuk aplikasi jaringan. Soket yang telah dibuat dapat 
digunakan untuk menunggu koneksi atau untuk memulai suatu koneksi. Soket yang Digunakan server untuk menunggu koneksi yang datang disebut passive socket, sedangkan socket yang digunakan oleh client untuk memulai suatu koneksi disebut active socket. Perbedaan antara passive dan active socket tergantung pada bagaimana aplikasi menggunakannya. Proses socket dapat dilihat pada Gambar 2 di bawah ini:

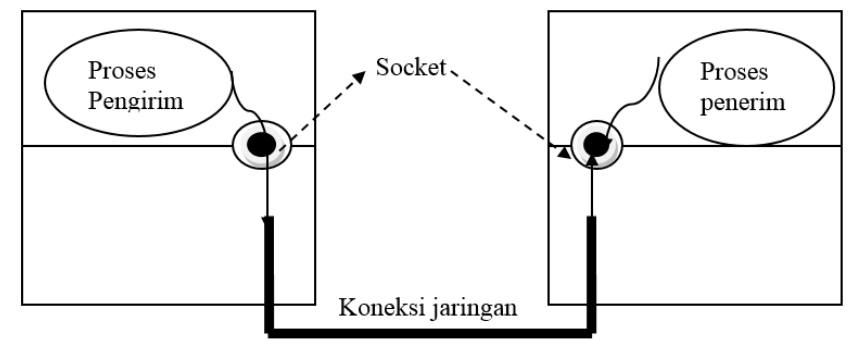

Gambar 2. Model IPC dengan Soket[5]

Agar suatu soket dapat berkomunikasi dengan soket lainnya, maka soket butuh diberi suatu alamat unik sebagai identifikasi. Alamat soket terdiri atas Alamat IP dan Nomor Port. Contoh alamat soket adalah 192.168.29.30: 3000, dimana nomer 3000 adalah nomor portnya. Alamat IP dapat menggunakan alamat Jaringan Lokal (LAN) maupun alamat internet. Jadi soket dapat digunakan untuk IPC pada LAN maupun Internet.

Nomor port dibutuhkan karena proses yang berjalan pada suatu komputer umumnya lebih dari satu. Sehingga dibutuhkan tambahan informasi sebagai identifikasi proses yang hendak dihubungi. Jika IP computer diibaratkan adalah nomor telepon suatu perusahaan, maka nomor port adalah nomor ekstensinya. Suatu proses yang hendak berkomunikasi dengan proses lain lewat mekanisme soket haruslah mengikatkan dirinya dengan salah satu port pada komputernya. Pengikatan diri ini disebut dengan binding.

Metode FIFO merupakan metode dimana barang pertama yang masuk berarti barang tersebutlah yang pertama keluar. Menurut "dengan metode FIFO, biaya persediaan dihitung berdasarkan asumsi bahwa barang akan dijual atau dipaki sendiri dan sisa dalam persediaan menunjukkan pembelian atau produksi yang terakhir".FIFO (First In First Out) merupakan algoritma penjadwalan non preemptive, tidak berprioritas. Setiap proses diberi jadwal eksekusi berdasarkan urutan waktu kedatangannya. Begitu proses mendapatakan jatah eksekusi maka proses akan dijalankan sampai selesai[8].

\subsection{Analisa sistem}

\section{HASIL DAN PEMBAHASAN}

Langkah awal dalam kerangkan penelitian ini adalah menganalisa permasalahan yang ada pada proses antrian yang terjadi pada layanan pembayaran uang kuliah di Unika, Dalam pembuatan sistem antrian layanan mahasiswa diperlukan adanya perancangan dan penganalisaan kebutuhan perangkat keras (hardware) yang dan perangkat lunak (software) yang akan digunakan agar aplikasi tersebut dapat berjalan seperti yang direncanakan.

Selain karena masalah antrian manual, pelayanan publik selalu mendapat sorotan negatif dari masyarakat. Mereka selalu mengira SDM (Sumber Daya Manusia) di kecamatan tidak bekerja secara total untuk melayani masyarakat. Padahal itu bukan satu-satunya alasan. Ada faktor lain yang menyebabkan SDM di instansi pemerintah selalu kewalahan dalam melakukan pelayanan, dan berujung pada berita negatif. Faktor tersebut adalah faktor manajemen waktu dan efisiensi. Dalam instansi pemerintah sangat sulit sekali untuk men-stabilkan ritme bekerja dari hari ke hari. Karena tugas dari pemerintah pusat juga selalu datang silih berganti. Solusinya adalah dengan menggunakan sistem aplikasi. Dengan adanya sistem, pekerjaan menjadi berkurang dan lebih efisien baik secara waktu dan tenaga.

\section{a. Perangkat Keras}

Perangkat keras adalah sistem utama dari sebuah sistem komputer secara fisik, yang terdiri dari komponen-komponen yang saling terkait, yaitu berupa masukan, proses, dan keluaran. Perangkat keras yang digunakan untuk membuat sistem antrian mahasiswa berbasis multimedia adalah seperangkat komputer dengan spesifikasi sebagai berikut:
a. Processor Intel Pentium $1.66 \mathrm{GHz}$
b. RAM (Random Access Memory) 512MB
c. Piranti masukan berupa mouse dan keyboard
d. Piranti keluaran berupa monitor 15", printer, dan soundsistem
e. Media penyimpanan seperti harddisk dengan kapasitas $80 \mathrm{~GB}$.

\section{b. Perangkat Lunak}

Perangkat lunak merupakan salah satu faktor yang sangat penting dalam pembuatan sistem antrian ini. Perangkat lunak yang digunakan dalam sistem antrian ini adalah :

a. Sistem operasi Microsoft WindowsXP ,Microsoft Windows2007 dan Microsoft Windows2008

b. Netbeans IDE 8.2, sebagai bahasa pemrograman dalam pembuatanaplikasi. 
c. Mysql, digunakan dalam pembuatandatabase.

masalah pada sistem. Tujuan perancangan sistem secara umum adalah untuk memberikan gambaran umum kepada pemakai (user) mengenai sistem informasi yang baru serta untuk memenuhi kebutuhan pemakai (user) dalam memperoleh dan mengolah informasi yangada. socket programming memungkinkan adanya komunikasi antara client dan server.

\section{c. Dukungan Jaringan}

Semua komputer harus terhubung dengan socket jaringan yang menjadi titik komunikasi antarmesin pada Internet Protocol, dan tentunya tanpa komunikasi ini, tidak akan ada pertukaran data dan informasi jaringan.

Penggunaan socket adalah anda dapat melakukan komunikasi antar proses/program melalui jaringan berbasis yang TCP/IP tentunya, bahkan dengan program lain yang berjalan pada platform non-unix seperti Microsoft Windows, sepanjang program tersebut berbicara dalam protokol transfer yang sama.

Berdasarkan diagram use case di bawah dapat dilihat bahwa pengguna dari sistem ini adalah staff dan mahasiswa. Staff dapat melakukan pemanggilan nomor antrian serta membatalkan nomor antrian jika peserta antrian tidak mendatangi loket pelayanan mahasiswa. Sedangkan mahasiswa dapat mendaftar menjadi peserta antrian serta mendapatkan struk. Tampilan Usecase diagram sistem antrian dapat dilihat pada gambar 3 di bawah ini.

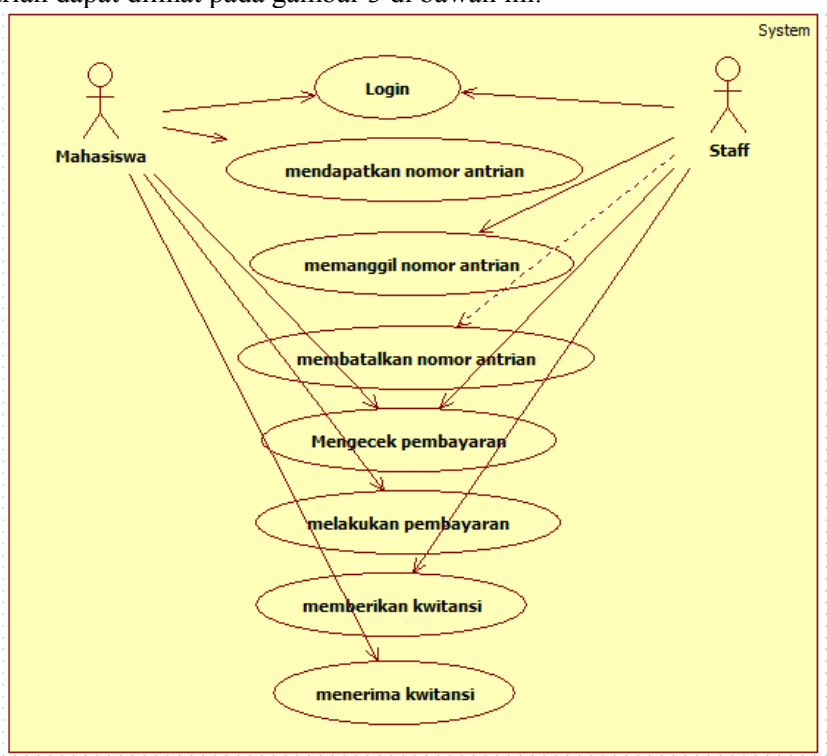

Gambar 3. Usecase Diagram Sistem Antrian

\section{e. Implementasi}

Implementasi interface (antarmuka) merupakan tahapan atau langkah-langkah untuk memenuhi kebutuhan user dalam berinteraksi dengan computer. Adapun interface pada sistem yang akan dibangun terdapat beberapa tampilan halaman. Pada setiap tampilan gambar di bawah ini:

Halaman beranda merupakan tampilan awal dari sistem ini yang menyediakan fitur-fitur apa saja yang tersedia. Tampilan halaman beranda dapat dilihat pada gambar 4 di bawah ini:

\section{Yok Anti}

\section{ANTRI GA PAKE LAMA}

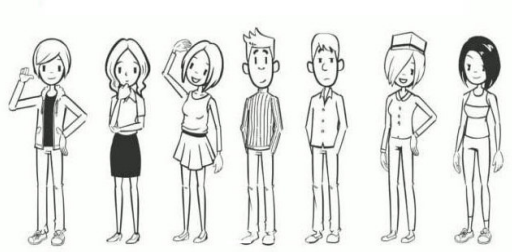

Gambar 4: Halaman Beranda

Menu ini terdiri dari form login ke dalam sistem yang dapat digunakan untuk semua user admin,mahassiwa dan staff. Tampilan menu login dapat dilihat pada gambar 5. 


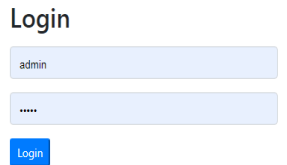

Gambar 5 : Tampilan Halaman Login

Dimana pada menu form ini admin dapat mengisi kode prodi di setiap fakultas. Tampilan form prodi dapat dilihat pada gambar 6 di bawah ini:

\section{Yok Ngantri}

\section{Prodi Mahasiswa Kategori Biaya Antrian Transaksi Logout}

Prodi

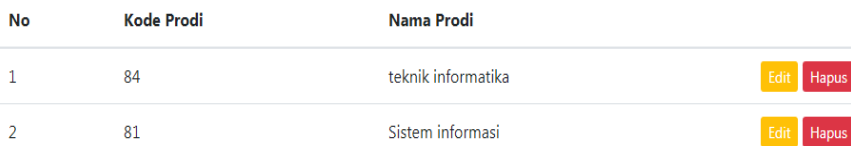

Gambar 6 : Tampilan Halaman Prodi

Pada form ini admin dapat mengisi data mahasiswa yang mengambil nomor antrian. Tampilan form halaman mahasiswa dapat dilihat pada gambar 7.

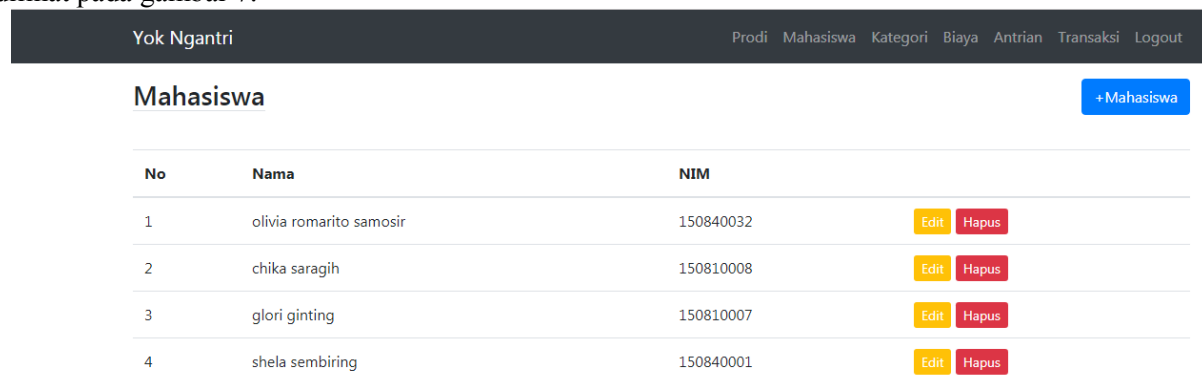

Gambar 7 : Tampilan Halaman Mahasiswa

Pada form ini admin akan mengisi nama kategori pembayaran yang akan dilakukan oleh mahasiswa. Tampilan halaman kategori dapat dilihat pada gambar 8 di bawah ini:

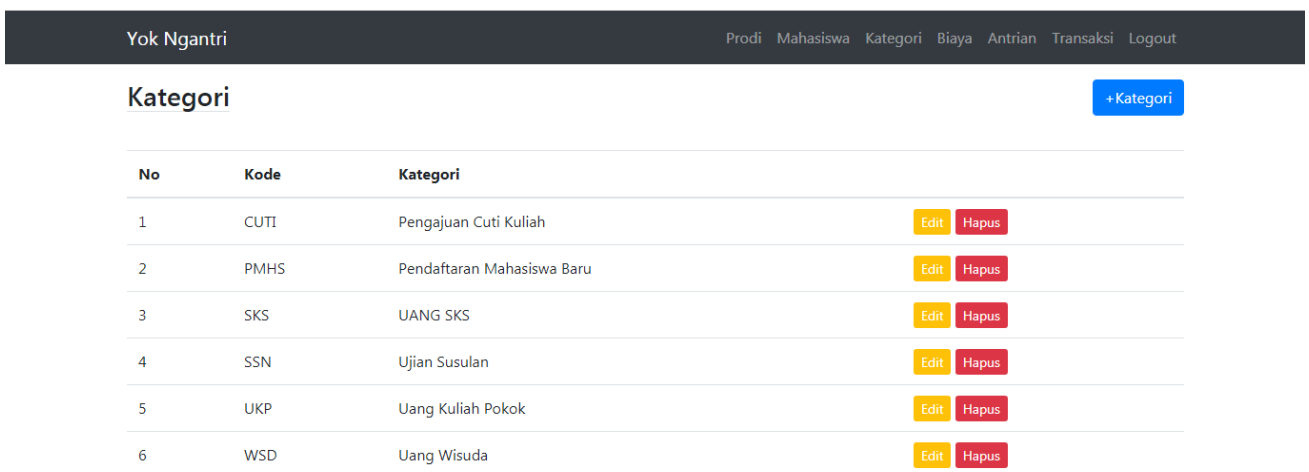

Gambar 8 : Tampilan Halaman Kategori

Pada form ini dimana admin dapat mengisi data mahasiswa yang melakukan pembayaran. Tampilan halaman biaya dapat dilihat pada gambar 9 berikut: 
Biaya

\begin{tabular}{lllllll}
\hline No & NIM & Nama & Kategori & Biaya & Batas & \\
\hline 1 & 150840001 & shela sembiring & Uang Kulliah Pokok & RP. 1,050,000 & 2019-08-31 & Ealt Hapus \\
\hline
\end{tabular}

Gambar 9 : Tampilan pada biaya

Pada form antrian dimana admin dapat melihat daftar nomor antrian yang diambil mahasiswa. Tampilan halaman antrian dapat dilihat pada gambar 10 berikut:

\section{Yok Ngantri \\ Prodi Mahasiswa Kategori Biaya Antrian Transaksi Logout}

$07 / 31 / 2019$

Proses

Antrian Rabu, 31 Juli 2019

No

No Antrian

Tanggal

Jam

Status

Gambar 10 : Tampilan Halaman Antrian

Pada form ini admin dapat melihat laporan transaksi yang sudah dibayar oleh mahasiswa dan pembayaran yang belum dilakukan oleh mahasiswa. Tampilan halaman transaksi dillihat pada gambar 11 berikut:

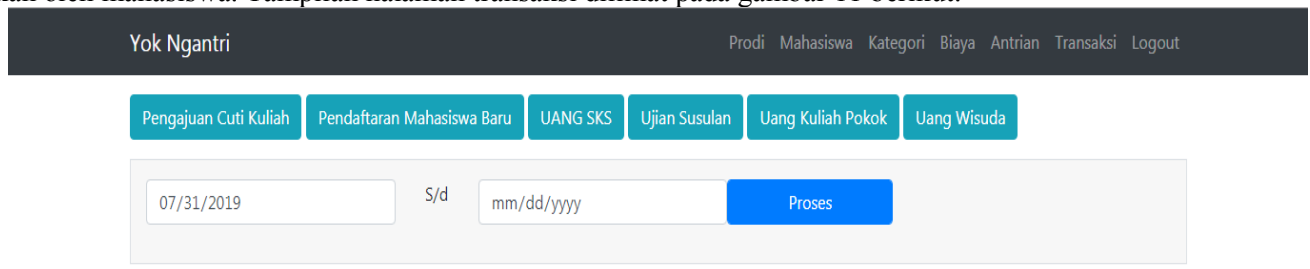

Transaksi Rabu, 31 Juli 2019

\begin{tabular}{lllllll} 
No & NIM & Nama & Kode Kategori & Biaya & Denda & Total \\
\hline 1 & \multirow{2}{*}{150840001} & mayshela & WSD & RP. 800,000 & RP. 80,000 & RP. 880,000 \\
\hline & & & & Total Biaya & Rp. 800,000
\end{tabular}

Gambar 11 : Tampilan Halaman Transaksi

Pada form halaman biaya diaman staff dapat melihat total pembayaran yang diambil oleh mahasiswa. Tampilan halaman biaya dapat dilihat pada gambar 12 berikut:

Yok Ngantri $\quad$ Biaja Antrian Transiksi logout

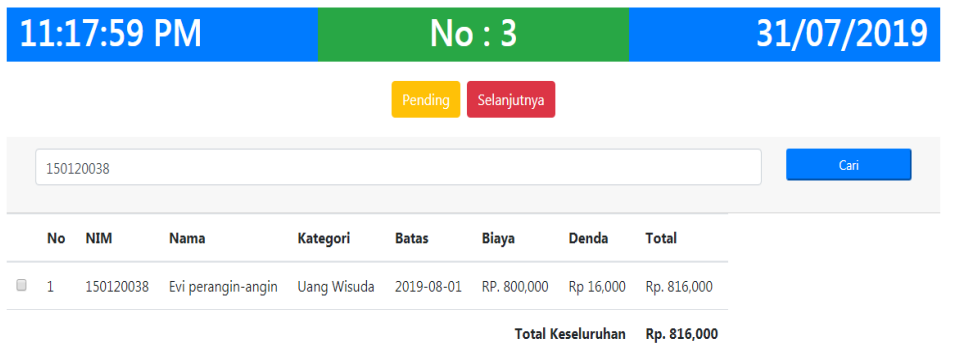

Gambar 12 : Tampilan Halaman Biaya

Pada form ini dimana staff dapat melihat nomor antrian yang diambil oleh mahasiswa dan jika nomor antrian tidak ada maka staff dapat merubah status antrian mahasiswa. Tampilan halaman antrian dapat dilihat pada gambar 13 berikut: 
Antrian Rabu, 31 Juli 2019

No

150120038

150840001

150840001

170810013

$\begin{array}{lccc}\text { Tanggal } & \text { Jam } & \text { Status } & \\ \text { Evi perangin-angin } & 7 & 2019-07-31 & 08: 35: 00 \\ \text { mayshela } & 8 & 2019-07-31 & 08: 40: 00 \\ \text { mayshela } & 8 & 2019-07-31 & 08: 40: 00 \\ \text { Rio simarmata } & 9 & 2019-07-31 & 08: 45: 00\end{array}$

Gambar 13 : Form Halaman Antrian

Form halaman transaksi dimana staff dapat melihat pembayraan yanng akan dilakukan oleh mahasiswa. Tampilan halaman form transaksi dapat dilihat pada gambar 14 berikut:

Yok Ngantri

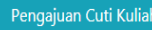

\section{Pendaftaran Mahasiswa Ba}

\section{Biaya Antrian Transaksi Logout}

\section{UANG SKS Ujian Susulan Uang Kuliah Pokok Uang Wisuda}

Proses

Transaksi Rabu, 31 Juli 2019

\begin{tabular}{|c|c|c|c|c|c|c|}
\hline No & NIM & Nama & Kode Kategori & Biaya & Denda & Total \\
\hline 1 & 150840001 & mayshela & SSN & RP. 440,000 & RP. 88800 & RP. 448,800 \\
\hline
\end{tabular}

Gambar 14 : Form Halaman Transaksi

Pada form ini mahasiswa mengambil nomor antrian dan memilih jenis pembayaran yang akan dilakukan. Tampilan form halaman antrian dapat dilihat pada gambar 15 berikut:

Ambil Nomor Antrian

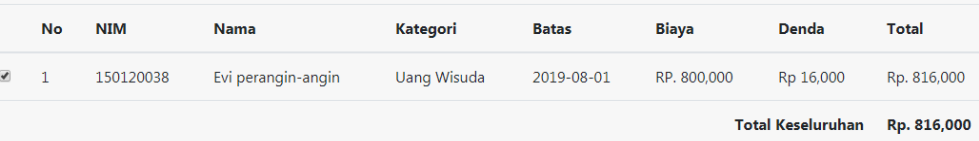

Gambar 15 : Form Halaman Antrian

\section{KESIMPULAN}

Kesimpulan yang dapat diambil dalam penelitian tentang model antrian FIFO (First-In First-Out) berbasis multimedia ini adalah sebagai berikut.

1. Sistem antrian yang dibangun dengan menggunakan teknologi komputer, dapat membantu mahasiswa untuk mendapat pelayanan dengan cepat.

2. Sistem antrian yang dibangun untuk universitas dapat memberikan pelayanan kepada mahasiswa secara efisien dan teratur.

3. Sistem antrian mahasiswa ini dibuat menggunakan teknologi komputer dapat membantu mahasiswa untuk mengetahui nomor antrian dan dapat mengetahui informasi nomor antrian yang sedang dilayani.

4. Program ini menggunakan model antrian FIFO (first-in first-out) yang artinya mahasiswa yang mendapatkan nomor antrian terlebih dahulu maka mahasiswa tersebut dapat dilayani lebih dulu. 


\section{DAFTAR PUSTAKA}

[1] R. N. Hakim, R. Marwati, and D. Rachmatin, "Program Aplikasi Sistem Antrian Multiserver Bank dengan Vacation ?/?/C," J. EurekaMatika, vol. 6, no. 1, pp. 9-22, 2018.

[2] A. M. H. Pardede, "SIMULASI ANTRIAN PELAYANAN NASABAH BANK MENGGUNAKAN METODE HYPEREXPONENTIAL,” Journal Information System Development (ISD), 2018. [Online]. Available: https://ejournal.medan.uph.edu/index.php/isd/article/view/163. [Accessed: 22-Jan-2020].

[3] J. E. B and W. Angwarmasse, "MODEL ANTRIAN FIFO (FIRST-IN FIRST-OUT) PADA PELAYANAN MAHASISWA FAKULTAS TEKNIK UNIVERSITAS JANABADRA BERBASIS MULTIMEDIA,” J. Tek., pp. 151-157, 2014.

[4] Andika, A. M. H. Pardede, and Novriyenni, "Simulasi antrian pelayanan bank menggunakan metode eksponensial," J. Sist. Inf. Kaputama, vol. 2, no. 1, pp. 9-19, 2018.

[5] M. Romzi, Logika dan Algoritma, no. tahun 1736. 2012.

[6] L. Sitorus, "Algoritma dan Pemrograman," Andi Yogyakarta, 2015. [Online]. Available: https://books.google.co.id/books?id=MRHwCgAAQBAJ\&printsec=frontcover\&dq=inauthor:\%22Lamhot+Sitorus $\% 22 \& \mathrm{hl}=$ en\&sa=X\&ved=0ahUKEwjiz6iljZfnAhVp7XMBHYf7C0QQ6AEIKjAA\#v=onepage\&q\&f=false. [Accessed: 22-Jan-2020].

[7] A. P. Windarto, H. Harumy, and I. Sulistianingsih, "Belajar Dasar Algoritma \& Pemrograman C++," no. January, pp. 1-9, 2016.

[8] Y. Novianto, "MODEL SISTEM ANTRIAN FIFO (FIRST-IN FIRST-OUT) PADA PELAYANAN FRONT OFFICE KEPADA MAHASISWA (STUDI KASUS: STIKOM Dinamika Bangsa)," Jurnal Processor, 2015. [Online]. Available: http://ejournal.stikom-db.ac.id/index.php/processor/article/view/87. [Accessed: 22-Jan-2020]. 